DOI: 10.1136/annrheumdis-2018-eular.6360

\section{SAT0246 AT WHICH POINT AND FOR WHICH REASONS ARE ORAL MTX FORMULATIONS SWITCHED TO INJECTABLE ONES IN RA PATIENTS? COMBINED RESULTS FROM 3 INDEPENDENT OBSERVATIONAL AND CLINICAL TRIALS}

R.-M. Flipo ${ }^{1,2}$, A. Saraux ${ }^{3}$, C. Hudry ${ }^{4,5}$, C. Gaujoux-Viala ${ }^{6}$, E. Senbel ${ }^{7}$, S. Tropé ${ }^{8}$ E. Zinovieva ${ }^{9,9}$, H. Herman-Demars ${ }^{9} .{ }^{1}$ Rheumatology department, CHRU Roger Salengro, ${ }^{2}$ University, Lille, ${ }^{3}$ Rheumatology department, CHU La Cavale Blanche, Brest, ${ }^{4}$ Rheumatology Department, Cochin Hospital, ${ }^{5}$ Institut de Rhumatologie Paris 8, Paris, ${ }^{6}$ Rheumatology department, CHU Carémeau, Nîmes, ${ }^{7}$ Rheumatology office, Marseille, ${ }^{8}$ ANDAR Patients' association, Montpellier, ${ }^{9}$ Medical Department, Nordic Pharma, Paris, France

Background: MTX is considered as a cornerstone in RA treatment since the 1990s and its injectable forms have proven their enhanced clinical and pharmacological efficacy and safety in case of insufficient response or poor tolerance of oral formulations. Few data are available considering the timepoint at which the route of administration is changed in current practice.

Objectives: The objective of this work was to investigate across 3 independent trials if there was a consistency in patterns of MTX oral ->injectable switches in terms of RA characteristics, MTX dosages (before and after the switch) and reasons of passage.

Methods: Three trials were considered for this work: 1/STRATEGE (observational study designed to investigate the therapeutic strategies used in current practice in RA patients insufficiently responding to initial MTX monotherapy), 2/APRiM (observational study aimed to investigate the treatment adherence of RA patients switching from oral to injectable MTX or between two different MTX prefilled syringes) and 3/SELFi (phase III randomized trial aiming to compare a new MTX autoinjector to the historical MTX prefilled syringe in terms of treatment adherence and functional capacity in RA patients at 6 months). In all three studies we selected baseline data concerning patients switching from oral to injectable MTX at the inclusion visit.

Results:

\begin{tabular}{llll}
\hline & STRATEGE & APRiM & SELFi \\
& $\mathrm{N}=151$ & $\mathrm{~N}=270$ & $\mathrm{~N}=98$ \\
\hline RA duration, years (mean \pm SD) & $4.9 \pm 6.1$ & $6.6 \pm 8.1$ & $4.5 \pm 5.9$ \\
(median (min;max)) & $2.8(0.0 ;$ & $3.0(0.0 ;$ & $2.0(0.2 ;$ \\
& $29.0)$ & $40.0)$ & $30.5)$ \\
MTX treatment duration, years (mean $\pm \mathrm{SD})$ & $3.6 \pm 4.5$ & $3.3 \pm 4.2$ & $2.5 \pm 2.8$ \\
(median (min;max)) & $1.9(0.0 ;$ & $1.4(0.0 ;$ & $1.4(0.1 ;$ \\
& $24.3)$ & $23.6)$ & $15.4)$ \\
DAS28 (mean $\pm S D$ ) & $4.4 \pm 0.9$ & $3.9 \pm 0.9$ & $3.5 \pm 1.2$ \\
MTX oral dosage at $\mathrm{V} 0, \mathrm{mg} / \mathrm{wk}$ (mean $\pm \mathrm{SD})$ & $15.3 \pm 3.7$ & $15.0 \pm 4.1$ & $14.8 \pm 3.8$ \\
MTX injectable dosage at the end of $\mathrm{V} 0, \mathrm{mg} / \mathrm{wk}$ & $17.0 \pm 4.0$ & $16.3 \pm 3.8$ & $17.0 \pm 4.0$ \\
(mean $\pm S D$ ) & & & \\
Distribution MTX dosage unchanged/raised/ & $50 \% / 45 \% /$ & $62 \% / 34 \% /$ & $51 \% / 42 \% /$ \\
reduced & $5 \%$ & $4 \%$ & $7 \%$ \\
\hline
\end{tabular}

Consistent data were observed across the three considered trials concerning the oral/injectable MTX switch. It occurs after about 3 years of treatment, at a DAS28 of 4 and at an average dose of $15 \mathrm{mg} / \mathrm{wk}$ (which is consistent with bioavailability data shown before). In most situations, MTX dosage is unchanged or very slightly raised at the switch timepoint. The main switch reasons were "non-achievement of treatment target" and "RA worsening", the safety reasons were mentioned only in $5 \%$ of cases.

Conclusions: Our work showed a consistent pattern across 3 independent trials concerning the oral/injectable MTX switch. It generally occurs at $15 \mathrm{mg} / \mathrm{wk}$, the new injectable dosage being either unchanged or very slightly raised as compared to the last oral one. Surprisingly, the MTX route of administration seems to be modified mostly for efficacy reasons, safety issues being anecdotal.

\section{REFERENCE:}

1 Schiff MH, et al. Ann Rheum Dis 2014.

Disclosure of Interest: R.-M. Flipo Consultant for: Nordic Pharma, A. Saraux Consultant for: Nordic Pharma, C. Hudry Consultant for: Nordic Pharma, C. Gaujoux-Viala Consultant for: Nordic Pharma, E. Senbel Consultant for: Nordic
Pharma, S. Tropé Consultant for: Nordic Pharma, E. Zinovieva Employee of: Nordic Pharma, H. Herman-Demars Employee of: Nordic Pharma DOI: 10.1136/annrheumdis-2018-eular.3709

\section{SAT0247 IMPACT OF GLUCOCORTICOIDS ON EFFICACY AND SAFETY OF TOFACITINIB WITH AND WITHOUT METHOTREXATE AND ADALIMUMAB WITH METHOTREXATE FOR RHEUMATOID ARTHRITIS: RESULTS FROM A PHASE 3B/4 RANDOMISED TRIAL}

R. Fleischmann ${ }^{1}$, J. Wollenhaupt ${ }^{2}$, S. Cohen ${ }^{1}$, J. S. Smolen ${ }^{3}$, P. Dahl ${ }^{4}$, N. likuni ${ }^{5}$, H. Shi ${ }^{6}$, S. Tatulych ${ }^{7}$, L. Takiya ${ }^{6} .{ }^{1}$ Metroplex Clinical Research Center and University of Texas Southwestern Medical Center, Dallas, TX, United States,

${ }^{2}$ Schön-Klinik Hamburg-Eilbek Teaching Hospital of the University of Hamburg, Hamburg, Germany, ${ }^{3}$ Medical University of Vienna and Heitzing Hospital, Vienna, Austria, ${ }^{4}$ Pfizer Inc, Ballerup, Denmark, ${ }^{5}$ Pfizer Inc, New York, NY, ${ }^{6}$ Pfizer Inc, Collegeville, PA, ${ }^{7}$ Pfizer Inc, Groton, CT, United States

Background: Tofacitinib is an oral Janus kinase inhibitor for the treatment of rheumatoid arthritis (RA). Glucocorticoids (GC) are an established therapy in RA that are often used to rapidly reduce pain and inflammation while awaiting the effects of disease-modifying antirheumatic drugs.

Objectives: A post hoc analysis to describe the impact of background GC on the efficacy and safety of tofacitinib with and without methotrexate (MTX) and adalimumab (ADA) with MTX in ORAL Strategy.

Methods: ORAL Strategy (NCT02187055) was a 1-year, double-blind, Phase $3 \mathrm{~b} / 4$, head-to-head, non-inferiority randomised controlled trial in adult patients (pts) with active RA despite MTX therapy. Pts were randomised 1:1:1 to receive tofacitinib $5 \mathrm{mg}$ twice daily (BID; tofa mono), tofacitinib $5 \mathrm{mg} \mathrm{BID} \mathrm{+} \mathrm{MTX} \mathrm{(tofa}$ + MTX) or subcutaneous ADA $40 \mathrm{mg}$ every other week + MTX (ADA+MTX). Pts receiving low-dose GC ( $\leq 10 \mathrm{mg} /$ day prednisone or equivalent) before enrolment maintained a stable dose throughout the study period. The following efficacy endpoints were assessed through Month 12 for pts receiving tofa mono, tofa+MTX and ADA+MTX with/without GC: ACR20, ACR50 and ACR70 response rates, proportions of patients achieving low disease activity (LDA; DAS28-4[ESR] $\leq 3.2)$ and remission (DAS28-4[ESR]<2.6) and change from baseline (BL) in HAQ-DI ( $\triangle \mathrm{HAQ}$-DI). Safety endpoints were evaluated throughout the study and included adverse events (AEs), serious AEs (SAEs), discontinuations due to AEs and serious infection events (SIEs).

Results: 1146 patients were randomised and treated; low-dose BL GC were received by 228/384 (59.4\%) pts receiving tofa mono (mean [SD] BL GC dose: 7.5 [13.7] mg/day), 215/376 (57.2\%) pts receiving tofa+MTX (mean [SD] BL GC dose: 6.5 [2.5] mg/day) and 223/386 (57.8\%) pts receiving ADA+MTX (mean [SD] BL GC dose: 6.4 [2.6] mg/day). BL demographics and disease characteristics were generally similar across treatment groups, regardless of BL GC use. Efficacy endpoints (ACR50 response rate, LDA and remission rates, $\triangle \mathrm{HAQ}$-DI) were generally similar for each treatment group when stratified by GC use (figure 1, table 1; similar results were seen for ACR20/70 response rates - data not shown). GC use did not appear to be associated with higher rates of $A E s$, discontinuations due to $A E s$, SIEs and SAEs; some AE rates were higher with MTX than without MTX (table 2). SIEs in pts using GC included herpes zoster ( $\mathrm{HZ}$; tofa mono, $n=2$ ) and tuberculous meningitis (tofa+MTX, $n=1$ ); in pts not using GC, there was 1 event each of cytomegalovirus chorioretinitis (tofa+MTX), pulmonary TB (tofa+MTX), HZ (ADA + MTX) and varicella (ADA+MTX).
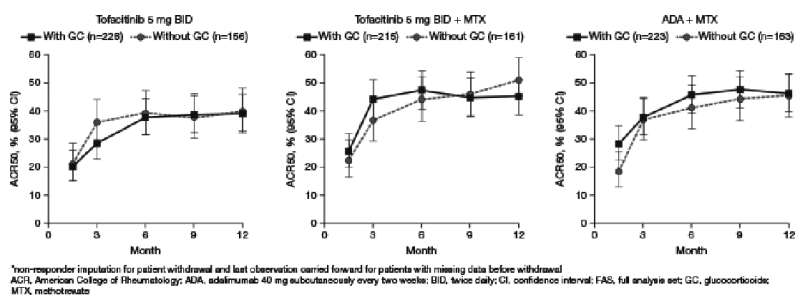

Figure 1. Proportion of patients achieving ACR50 response according to treatment group and GC use (FAS, with imputation*) 
Table 1. Response rates in patients over 12 months, with or without baseline GC (FAS)

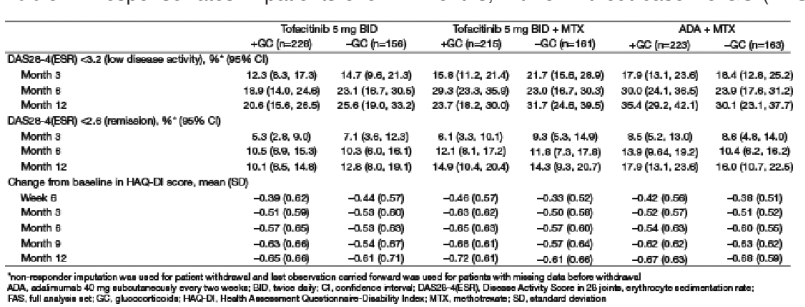

Table 2. Summary of AEs, discontinuations due to AEs, SAEs and SIEs over 12 months

\begin{tabular}{|c|c|c|c|c|c|c|}
\hline \multirow[b]{3}{*}{ AEs, n p(s) } & \multicolumn{2}{|c|}{ Toffectínib $5 \mathrm{mg}$ BlD } & \multicolumn{2}{|c|}{ Tofectifilib $5 \mathrm{mg}$ Bl + + MTX } & \multicolumn{2}{|c|}{$A D A+M T X$} \\
\hline & $+9 C(n=228)$ & $-\operatorname{se}(n=158)$ & $+6 C(n=215)$ & $-6 C n=181)$ & $+6 C(n=229)$ & $-\operatorname{GCC}(n=1893)$ \\
\hline & $\pi 7($ (93.8) & $57(30.5)$ & $80(41.9)$ & $74(40.0)$ & $80(90.6)$ & $86(4+1.7)$ \\
\hline 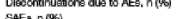 & $6(2.6)$ & $\therefore$ & $1(0.5)$ & 42.9 & $4(4.8)$ & $6(a .7)$ \\
\hline 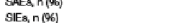 & $\begin{array}{l}3(.19) \\
2(0.8)\end{array}$ & 11(7.1) & $\begin{array}{l}17(0.8) \\
1(0.5)\end{array}$ & 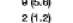 & $5(2.2)$ & 88.49 \\
\hline 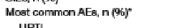 & & & & & & \\
\hline Nasophanngitis & $\begin{array}{l}13(57) \\
114.98\end{array}$ & $\begin{array}{l}12.77 \\
11(7.1)\end{array}$ & $\begin{array}{lll} & \end{array}$ & $\begin{array}{l}17(10.6) \\
40.9\end{array}$ & (7.0.9 & $\begin{array}{l}12(7.4) \\
8(5,5)\end{array}$ \\
\hline 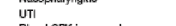 & $\begin{array}{l}3(1.3) \\
3(1.3)\end{array}$ & $n(5.1)$ & $\begin{array}{l}120.60 .77 \\
10(4)\end{array}$ & $\begin{array}{l}5(3.1) \\
5.11\end{array}$ & $8(3.8)$ & 86.97 \\
\hline Blood CFK increased & $5(2.2)$ & $\begin{array}{l}5(3.1) \\
5(3.2)\end{array}$ & 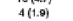 & 815.09 & $\begin{array}{l}0.01 \\
+(0.4)\end{array}$ & $4(2.5)$ \\
\hline ALT increasead & $4(1.6)$ & $4(2.6)$ & $10\left(4 . T_{i}\right.$ & $13(8.1)$ & $18(0.1)$ & $8(4.8)$ \\
\hline ABT inoreased & $2(0.0)$ & $2(13)$ & $8(2,8)$ & $10(8.2)$ & $11(4.9)$ & \\
\hline
\end{tabular}

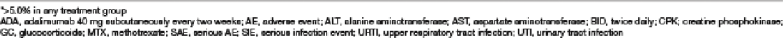

Conclusions: In pts with RA, concomitant stable GC use did not appear to impact the efficacy of tofacitinib $5 \mathrm{mg}$ BID \pm MTX or ADA+MTX. The finding that GC use was not associated with higher AE rates was unexpected and of interest.

Acknowledgements: Study sponsored by Pfizer Inc. Medical writing support was provided by $\mathrm{C}$ Viegelmann of $\mathrm{CMC}$ and funded by Pfizer Inc.

Disclosure of Interest: R. Fleischmann Grant/research support from: AbbVie, Amgen, AstraZeneca, Bristol-Myers Squibb, Celltrion, Eli Lilly, Genentech, GSK, Janssen, Novartis, Pfizer Inc, Sanofi-Aventis, UCB, Consultant for: AbbVie, Amgen, AstraZeneca, Bristol-Myers Squibb, Celltrion, Eli Lilly, Genentech, GSK, Janssen, Novartis, Pfizer Inc, Sanofi-Aventis, UCB, J. Wollenhaupt Consultant for: Pfizer Inc, Speakers bureau: Pfizer Inc, S. Cohen Grant/research support from: AbbVie, Amgen, Astellas, Bristol-Meyers Squibb, Eli Lilly, Genentech, Gilead, Janssen, Novartis, Pfizer Inc, Roche, Sandoz, Consultant for: AbbVie, Amgen, Astellas, Bristol-Meyers Squibb, Eli Lilly, Genentech, Gilead, Janssen, Novartis, Pfizer Inc, Roche, Sandoz, J. Smolen Grant/research support from: AbbVie, Eli Lilly, Janssen, MSD, Pfizer Inc, Roche, Consultant for: AbbVie, Amgen, AstraZeneca, Astro, Celgene, Celltrion, Eli Lilly, GSK, ILTOO, Janssen, Medlmmune, MSD, Novartis-Sandoz, Pfizer Inc, Roche, Samsung, Sanofi, UCB, Speakers bureau: AbbVie, Amgen, AstraZeneca, Astro, Celgene, Celltrion, Eli Lilly, GSK, ILTOO, Janssen, Medlmmune, MSD, Novartis-Sandoz, Pfizer Inc, Roche, Samsung, Sanofi, UCB, P. Dahl Shareholder of: Pfizer Inc, Employee of: Pfizer Inc, N. likuni Shareholder of: Pfizer Inc, Employee of: Pfizer Inc, H. Shi Shareholder of: Pfizer Inc, Employee of: Pfizer Inc, S. Tatulych Shareholder of: Pfizer Inc, Employee of: Pfizer Inc, L. Takiya Shareholder of: Pfizer Inc, Employee of: Pfizer Inc

DOI: 10.1136/annrheumdis-2018-eular.1533

\section{SAT0248 A MULTICENTER STUDY ASSESSING THE EFFICACY AND SAFETY OF REPOSITORY CORTICOTROPIN INJECTION IN PATIENTS WITH RHEUMATOID ARTHRITIS: PRELIMINARY INTERIM DATA FROM THE OPEN-LABEL TREATMENT PERIOD}

R. Fleischmann ${ }^{1}$, D. E. Furst ${ }^{2}$, R. Brasington ${ }^{3}$, E. Connolly-Strong ${ }^{4}$, J. Liu ${ }^{4}$, M. E. Barton ${ }^{4} .{ }^{1}$ Southwestern Medical Center, University of Texas, Dallas, ${ }^{2}$ David Geffen School of Medicine, University of California at Los Angeles, Los Angeles, ${ }^{3}$ School of Medicine, Washington University, St. Louis, ${ }^{4}$ Mallinckrodt, ARD Inc, Bedminster, United States

Background: Rheumatoid arthritis (RA) is an autoimmune disorder associated with chronic inflammation that is commonly treated with disease-modifying antirheumatic drugs (DMARD) and corticosteroids. Repository corticotropin injection $(\mathrm{RCl})$ is approved in the United States as adjunctive therapy for short-term administration (during an acute episode or exacerbation) in RA (selected cases may require low dose maintenance therapy).

Objectives: This is an interim analysis from a multicenter, 2-part study evaluating the efficacy and appropriate duration of $\mathrm{RCl}$ therapy in patients with persistently active RA despite receiving 1-2 DMARDs and corticosteroids.

Methods: The study includes a 12-week open-label treatment period followed by a 12-week double-blind randomized maintenance phase for patients who achieve low disease activity (LDA) at Week 12. During the open-label period, all enrolled patients received $\mathrm{RCI} 80 \mathrm{U}$ subcutaneously (SC) twice per week. The primary endpoint was the proportion of patients that achieved LDA (ie, disease activity score with 28 joint count and erythrocyte sedimentation rate [DAS28-ESR] score $<3.2)$ at Week 12. The secondary endpoints were proportion of patients that maintained LDA from Week 12 to Week 24, time to disease activity flare, safety, and tolerability. Disease activity was also assessed by the proportion of patients that achieved improvements in American College of Rheumatology (ACR)20 ACR50, and ACR70 scores at Week 12

Results: As of December 18, 2017, 45 patients had completed the 12-week open-label treatment period of the study, and 12 patients had discontinued; $77.8 \%$ were female, with a mean age of 57 years. Patient baseline characteristics and the results of the primary and select secondary endpoints are presented in table 1, demonstrating that $\mathrm{RCl}$ allowed the majority of patients with RA to achieve LDA at Week 12. To date, 21 adverse events (AEs) and 1 serious AE (chest pain) have been reported. The most common AEs were headache (3), urinary tract infection (2), and fall (2).

Table 1. Patient Baseline and Endpoint Results at Week 12

\begin{tabular}{lll}
\hline Parameter & Baseline & $\begin{array}{l}\text { Week } \\
\mathbf{1 2}\end{array}$ \\
\hline DAS28-ESR Score, mean & & 3.6 \\
Tender Joint Count, mean & 6.5 & 3.5 \\
Swollen Joint Count, & 16.4 & 3.2 \\
mean & 12.5 & \\
LDA (DAS28-ESR <3.2) & & $55.6 \%$ \\
ACR20 & & $84.4 \%$ \\
ACR50 & & $57.8 \%$ \\
ACR70 & & $35.6 \%$ \\
\hline
\end{tabular}

Conclusions: Interim results from this ongoing clinical trial suggest that $\mathrm{RCI}$ can potentially be a safe and effective treatment alternative to improve multiple meas ures of disease activity in patients with persistently active RA despite therapy with DMARDs and corticosteroids.

Acknowledgements: Editorial support was provided by MedLogix Communications, LLC, Itasca, IL, under the direction of the authors and was funded by Mallinckrodt ARD, Inc., Bedminster, NJ.

Disclosure of Interest: R. Fleischmann: None declared, D. Furst: None declared, R. Brasington: None declared, E. Connolly-Strong Shareholder of: Mallinckrodt, ARD Inc, Employee of: Mallinckrodt, ARD Inc, J. Liu Shareholder of: Mallinckrodt, ARD Inc, Employee of: Mallinckrodt, ARD Inc, M. Barton Shareholder of: Mallinckrodt, ARD Inc, Employee of: Mallinckrodt, ARD Inc DOI: 10.1136/annrheumdis-2018-eular.5768

\section{SAT0249 REDUCTION OF MONOCYTE ACTIVATION BY BOWEL CLEANSE AND ONE WEEK FASTING SUGGESTS PERMANENT PATHOGENETIC TRIGGERING FROM THE GUT IN RHEUMATOID ARTHRITIS}

T. Häupl ${ }^{1}$, T. Sörensen ${ }^{1}$, M. Boyer ${ }^{1}$, J. Scheder-Bieschin ${ }^{2}$, B. Smiljanovic ${ }^{1}$, N. Steckhan², G.-R. Burmester ${ }^{1}$, B. Stuhlmüller', C. Kessler ${ }^{2}$, M. Bonin ${ }^{1}$, A. Grützkau ${ }^{3}$, A. Michalsen ${ }^{2} .{ }^{1}$ Rheumatology, ${ }^{2}$ Internal and Complementary Medicine, Charité, ${ }^{3}$ Deutsches Rheuma Forschungszentrum, Berlin, Germany

Background: Fasting can improve clinical disease activity in rheumatoid arthritis (RA) [1], but mechanism involved are not clear. Recently, we demonstrated that monocytes in RA express transcriptome patterns of increased myelopoiesis, premature egress from bone marrow and reduced circulation time as indicators of permanent activation of the innate immune response [2].

Objectives: We investigated the influence of bowel cleanse and fasting on monocyte subpopulations in the blood to determine the extent of microbiota and gut immunity related triggering of chronic inflammation in RA.

Methods: RA patients $(n=22)$ and controls ( $n=12$, metabolic syndrome), who presented for fasting according to the Buchinger procedure (bowel cleanse with colonoscopy fluid), were analyzed for DAS28, CrP, differential blood count and high resolution cytometric phenotyping at baseline, day 3 , day 7 (end of fasting) and day 10. ImmunoClust was applied for automated cell clustering [3].

Results: Disease activity was strikingly decreased after fasting in virtually all RA patients (DAS28 from 4.24 to $3.17, \mathrm{p}<0.00005$ ) with significant reduction already after 3 days $(p<0.01)$. This was accompanied by a significant decline of $\mathrm{CrP}$ and ESR. Differential blood count revealed a slight decrease in total leukocytes and significant reduction of lymphocytes and eosinophils in RA. However, these blood changes were also observed but on a lower level in the metabolic controls. The most dominant and RA specific effect was a significant reduction of total monocytes when compared to RA baseline or to controls at day 10. Deep profiling of the monocyte compartment revealed reduced non-classical $\left(\mathrm{CD} 14^{+} \mathrm{CD} 16^{+}\right)$and intermediate $\left(\mathrm{CD} 14^{++} \mathrm{CD} 16^{+}\right)$monocytes prior to fasting in RA compared to controls and confirmed previous results [2]. Bowel cleanse and fasting induced a significant increase of these two monocyte subpopulations by absolute counts and even more by percentage of total monocytes. This indicates reduced recruitment to inflamed tissue and prolonged circulation with more cells differentiating from classical to non-classical monocytes in the blood [4]. The decrease of lymphocytes in RA patients after fasting was characterized by a dominant reduction of 